Aim To describe the clinical presentation and current management of FOP.

Methods A 7 year old boy with a history of hallux valgus, recurrent painful episodes of soft tissue swelling and new abnormal bone formation, was assessed clinically and radiologically.

Results Review of the clinical history and radiographs taken in infancy revealed the diagnosis of FOP. This had not been previously recognised, although he had been seen in a specialist Hallux Valgus clinic as a baby.

Conclusions As specific treatments are now becoming available for this life-limiting condition, it is essential that all neonatologists, paediatricians, paediatric oncologists and orthopaedic surgeons consider a diagnosis of FOP if a baby or child presents with bilateral hallux valgus and/or episodes of swelling with evidence of ossification. These children should now be referred to a paediatric metabolic bone clinic to consider genetic testing and for specialist management.

\section{G206(P) RECOGNISING THE RISK FACTORS: MISSED OPPORTUNITIES TO PREVENT RICKETS}

${ }^{1}$ FA Hutchings, ${ }^{2} \mathrm{~N}$ Oliver, ${ }^{1} \mathrm{~A}$ Thursby-Pelham, ${ }^{3} \mathrm{CP}$ Burren. ${ }^{1}$ Department of General Paediatrics, Bristol Royal Hospital for Children, Bristol, UK; ${ }^{2}$ Department of Paediatric Emergency Medicine, Bristol Royal Hospital for Children, Bristol, UK; ${ }^{3}$ Department of Paediatric Endocrinology, Bristol Royal Hospital for Children, Bristol, UK

\subsection{6/archdischild-2015-308599.200}

Aim Implementing the NICE guidance published in November 2014 for vitamin D supplementation of at-risk groups, including all children under-five years of age, would help reduce childhood rickets due to Vitamin D deficiency. Whilst awareness of Vitamin D is increasing, we often assume that UK infants have sufficient calcium dietary intake. This case series highlights rickets arising when insufficient dietary calcium compounds the effects of insufficient Vitamin D.

Methods We reviewed case-notes, biochemical and radiological data of four children diagnosed with rickets at our hospital during the past 18 months.

Results One child presented aged seven months with seizures. She had a prolonged corrected QT interval secondary to profound hypocalcaemia (corrected calcium $1.49 \mathrm{mmol} / \mathrm{L}$ ), and vitamin D Deficiency (vitamin D $<6 \mathrm{nmol} / \mathrm{L}$ ). The remaining three infants (aged 16-20 months) presented with bony deformities characteristic of rickets, and Vitamin D supplementation had recently been commenced in primary care. Total Vitamin D levels were $26.3,38.9$ and $51.1 \mathrm{nmol} / \mathrm{L}$ each with a significant proportion of the total Vitamin D as D2 consistent with supplementation. These three cases had normo-calcaemia (2.3$2.54 \mathrm{mmol} / \mathrm{L}$ ). Radiology showed rachitic changes. All cases had pigmented skin, were predominantly breastfed and had no vitamin D supplementation during the first year of life. The clinical and radiological rachitic changes were more marked than expected for the levels of Vitamin D. All were cow's milk allergic (confirmed on specific IgE testing) and were slow to wean, with prolonged breast feeding. The children had inadvertently been on low calcium diets without supplementation. All children have made good progress with subsequent appropriate calcium and vitamin D supplementation.

Conclusion This series illustrates commonly recognised risk factors for rickets, namely skin pigmentation, exclusive and prolonged breastfeeding, and the lack of Vitamin D supplementation. Undoubtedly the lack of vitamin D was contributory to the development of rickets and appropriate supplementation could have minimised the adverse skeletal effects. These cases also highlight that a calcium-deplete diet is an additive risk factor for the development of rickets. Infants with cow's milk protein allergy comprise a clinical group in whom it is important to consider the need for calcium supplementation alongside Vitamin D.

\section{G207(P) TO REVIEW THE OUTCOME OF HIP SCREENING ULTRASOUND SCAN (USS) FOR DEVELOPMENTAL DYSPLASIA OF HIP (DDH) IN HIGH RISK BABIES}

P Jain, M Ahmed. Paediatrics, Alexandra Hospital, Redditch, UK

10.1136/archdischild-2015-308599.201

Aim The aim of our study was to review the outcome of hip screening ultrasound scan in high risk babies for further evaluation of developmental dysplasia of hip in the district general hospital.

Methods This is a retrospective study. We looked at the outcome of the USS hip performed for the period of 18 months from June 2013 to October 2014 in our trust in high risk patient group with breech presentation, family history of $\mathrm{DDH}$, twin deliveries with one of the twin born with breech presentation and on the clinical suspicion after clinical examination of the hip. Data was collected using hospital notes, PACS system was used for USS results.

Results In total 553 USS hip was performed for further evaluation of DDH out of which only 4 scans were abnormal. Three of this abnormal scans were in babies born with breech presentation and one was in a baby who's mother had history of DDH needed intervention in past. Out of this 4 abnormal scans 3 scans were Graf Type IIa and one was Graf type D.

Conclusion In our experience we have observed a significantly low percentage of clinically relevant USS results for DDH even in selected high risk babies.

\section{Royal College of Nursing}

\section{G208 REFLECTIONS AND NEW DIRECTIONS IN CHILDREN AND YOUNG PEOPLE'S PALLIATIVE CARE}

${ }^{1} \mathrm{JE}$ Coad, ${ }^{1} \mathrm{~N}$ Ashley, ${ }^{1} \mathrm{C}$ Clay, ${ }^{1} \mathrm{C}$ Chamley, ${ }^{2} \mathrm{D}$ Widdas. ${ }^{1} \mathrm{C}$ ildren and Family Research, Coventry University, Coventry, UK; ${ }^{2}$ South Warwickshire NHS Foundation Trust, South Warwickshire NHS Foundation Trust, Warwickshire, UK

\subsection{6/archdischild-2015-308599.202}

In June 2010, the Department of Health (DoH) in the UK released a call to apply for funding to support projects focused on benefiting the lives of children and young people with palliative and complex health care needs and their families. A programme of work was subsequently developed from 2010-2014 including an innovative e-learning programme and important projects seeking to explore issues around competence of care skills and communication challenges in the field of children and young people with palliative care.

Aims The aim in this workshop is to share reflections from a recent narrative literature review as part of a programme of work which focused on confidence and competence of care skills. Results of the review will be shared but will provide a platform for critical debate around challenges and new directions in children and young people's palliative care. 